\title{
Tracking passive drifters in a high resolution ocean model: implications for interannual variability of larval krill transport to South Georgia
}

\author{
Sally E. Thorpe ${ }^{\mathrm{a}, \mathrm{b}, *}$, Karen J. Heywood ${ }^{\mathrm{a}}$, David P. Stevens ${ }^{\mathrm{c}}$, Mark A. Brandon ${ }^{\mathrm{b}, 1}$ \\ ${ }^{a}$ School of Environmental Sciences, University of East Anglia, Norwich NR4 7TJ, UK \\ ${ }^{\mathrm{b}}$ British Antarctic Survey, Natural Environment Research Council, High Cross, Madingley Road, Cambridge CB3 OET, UK \\ ${ }^{\mathrm{c}}$ School of Mathematics, University of East Anglia, Norwich NR4 7TJ, UK
}

Received 25 September 2002; received in revised form 3 September 2003; accepted 20 February 2004

\begin{abstract}
A particle tracking scheme that uses velocity output from an interannually varying forced run of a global ocean circulation model (Parallel Ocean Climate Model; POCM_4C) allows variability in the transport pathways across the Scotia Sea to South Georgia to be examined for the first time. The time-variant surface fluxes introduce realistic variability into the model velocity fields. This causes large variations in near-surface, mixed-layer transport from the Antarctic Peninsula region to South Georgia, an island in the southwest Atlantic sector of the Southern Ocean. The variability occurs on a variety of timescales with seasonal and longer periods of variability apparent in the 18 year time series of results. A quasi-four year period of variability is evident across the region in the sea surface temperature fields of POCM_4C and appears in the particle tracking results. This period, noted in other Southern Ocean data sets and ascribed to the Antarctic Circumpolar Wave, has been observed in the reproductive success of higher marine predators breeding on the island. The predicted oceanographic variability is likely to be significant for the South Georgia ecosystem by affecting the influx into the region of Antarctic krill (Euphausia superba), the main prey of the higher predators.
\end{abstract}

(C) 2004 Elsevier Ltd. All rights reserved.

Keywords: Ocean circulation; Variability; Model; Lagrangian drifters; Antarctic Circumpolar Current; Antarctic krill; Southern Ocean; Scotia Sea $\left(50-65^{\circ} \mathrm{S}, 65-30^{\circ} \mathrm{W}\right)$

\footnotetext{
*Corresponding author. Present address: British Antarctic Survey, Natural Environment Research Council, High Cross, Madingley Road, Cambridge CB3 0ET, UK.

E-mail address: seth@bas.ac.uk (S.E. Thorpe).

${ }^{1}$ Now at Department of Earth Sciences, The Open University, Walton Hall, Milton Keynes MK7 6AA, UK.
}

\section{Introduction}

Historically, the forcing of global ocean models with cyclical climatological fields has precluded studies of interannual variability. A new generation of numerical ocean models, however, uses time-variant surface fluxes thereby introducing 
realistic temporal oceanographic variability into the model output (e.g., Tokmakian and Challenor, 1999; Webb and de Cuevas, 2003). These simulations permit investigation of temporal variability on a variety of timescales in areas where hydrographic data are sparse (Thorpe et al., 2002) and allow examination of the potential impacts of this physical variability, for example on the local ecosystem. One such region where physical variability may be ecologically important is the Scotia Sea, southwest Atlantic Ocean. The island of South Georgia is located in the eastern Scotia Sea ( $\sim 54^{\circ} \mathrm{S}, 37^{\circ} \mathrm{W}$; Fig. 1$)$ and supports large breeding populations of higher marine predators. The reproductive success of the higher predators is interannually highly variable; this variability has been linked to temporal variability in the local abundance of the main prey of the predators, Antarctic krill (Euphausia superba) (Croxall et al., 1988, 1999; Boyd et al., 1994). It is believed that the Antarctic krill population at South Georgia is not self-sustaining, rather that it relies on influx of krill from known breeding areas upstream of South Georgia such as the Antarctic Peninsula, the South Orkney Islands and the Weddell Sea (e.g., Marr, 1962; Everson, 1984). Results from the Discovery Investigations carried out early last century showed a relationship between prevailing oceanographic conditions and interannual fluctuations in the size of scientific catches of Antarctic krill around South Georgia (Mackintosh, 1972; Baker, 1977). Years could be characterised as warm or cold depending on the sea surface temperature with substantially larger amounts of krill caught in the cold years. The warm and cold years were associated with changes in the concentration and extent of sea-ice and the regional oceanography of the Scotia Sea, in particular inflow of cold water from the Weddell Sea (Marr, 1962; Deacon, 1977). Variability in krill abundance has been observed in other regions of the Scotia Sea. At the South Shetland Islands, near the Antarctic Peninsula, variability in krill abundance has been linked to fluctuations in recruitment

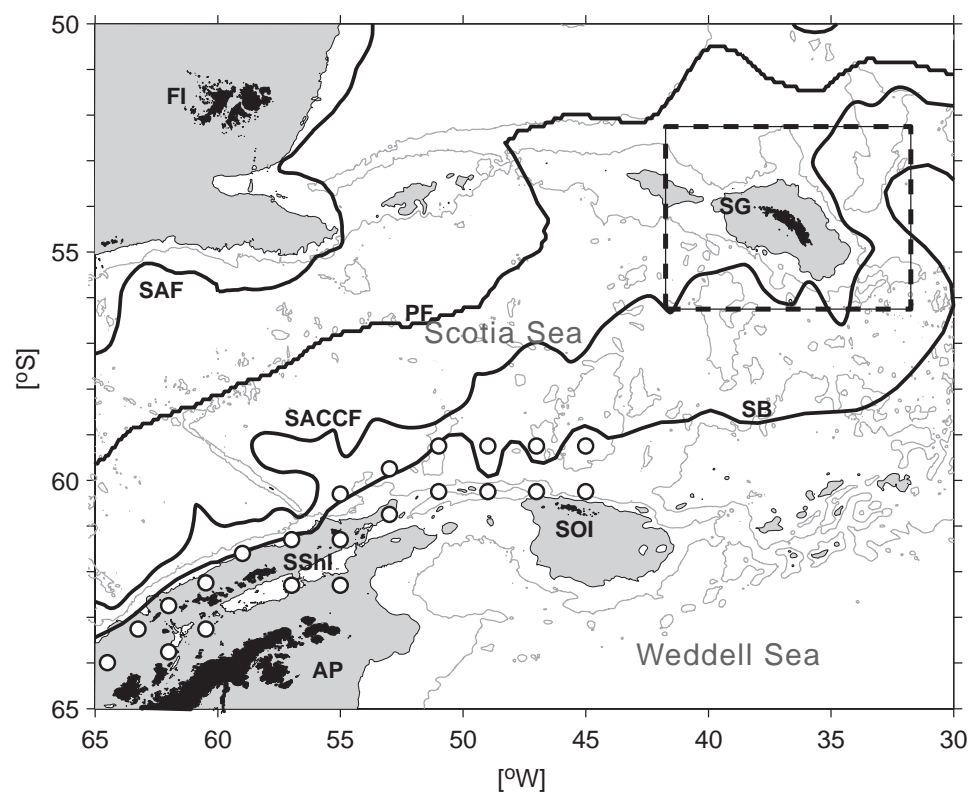

Fig. 1. Map of the Scotia Sea. Bathymetry shallower than $1000 \mathrm{~m}$ is shaded grey, the $3000 \mathrm{~m}$ isobath is marked (Smith and Sandwell, 1997). Thick solid lines indicate the mean positions of the Subantarctic Front (SAF) following Orsi et al. (1995), the Polar Front (PF) following Moore et al. (1997), the SACCF and the southern boundary of the ACC (SB), both from Thorpe (2001). Open circles mark the particle release sites, and a dashed line shows the area used to define particles reaching South Georgia. Land masses marked are AP-Antarctic Peninsula, FI-Falkland Islands, SG-South Georgia, SOI-South Orkney Islands, and SShI-South Shetland Islands. 
rate of juvenile krill (Siegel and Loeb, 1995). This has been suggested to be related to sea-ice extent and duration, both of which are potentially significant for krill reproduction and survival (Marr, 1962; Loeb et al., 1997; Siegel et al., 1998). At South Georgia, years of low krill abundance can be related to failure the previous year to recruit juvenile krill into the South Georgia population (Reid et al., 1999a,b). The Antarctic Peninsula region is considered an important source region for the South Georgia krill population and so propagation across the Scotia Sea to South Georgia of the abundance variability observed at the South Shetland Islands is expected. However, not all of the fluctuations in krill abundance observed at South Georgia can be accounted for by the krill variations at the Antarctic Peninsula (Murphy et al., 1998). Given the importance of the regional oceanic currents for the Scotia Sea marine ecosystem, oceanographic variability has the potential to be one of these additional sources (e.g., Mackintosh, 1972; Baker, 1977; Priddle et al., 1988; Murphy, et al., 1998) and it is this that we investigate in this paper.

South Georgia lies in the path of the Antarctic Circumpolar Current (ACC). The ACC is a major current consisting of at least four current cores associated with thermohaline fronts embedded in the generally eastward flowing background flow. The fronts are, from north to south, the Subantarctic Front, the Polar Front, the southern ACC front (SACCF) and the southern boundary of the ACC (Fig. 1). Of these, the SACCF is believed to play an important role in transport to South Georgia passing close to the Antarctic Peninsula and the southern shelf of South Georgia before wrapping around the northern shelf of the island (Orsi et al., 1995; Hofmann et al., 1998; Murphy et al., 1998; Thorpe et al., 2002, Fig. 1). Recent observations have recorded a large flux of Antarctic krill associated with the SACCF north of South Georgia (Murphy et al., 2004b). High levels of mesoscale variability are associated with the zonation of the ACC (e.g., Nowlin and Klinck, 1986; Chelton et al., 1990; Morrow et al., 1994; Moore et al., 1997). Longer period variability has also been observed in the ACC. The Antarctic Circumpolar Wave precesses eastward with the
ACC propagating anomalies in sea-ice extent, sea surface temperature, atmospheric sea level pressure and meridional wind stress with an apparent period in any one location of 4-5 years (Murphy et al., 1995; White and Peterson, 1996).

In this paper, we use output from a realistically forced 20 year run of the Semtner/Chervin Parallel Ocean Climate Model (POCM; Tokmakian and Challenor, 1999) to examine oceanographic variability in the Scotia Sea, focussing in particular on transport from the Antarctic Peninsula to South Georgia to question whether physical variability may play a role in the biological variability observed at South Georgia. Thorpe et al. (2002) showed that zonal movements of the SACCF north of South Georgia in another realistically forced global ocean circulation model can affect the transport of particles into the region northwest of South Georgia. Here, we investigate the effects of wider-scale, regional physical variability using a particle tracking scheme that uses time-varying velocity output from POCM.

\section{Model output and particle-tracking scheme}

POCM is an eddy-permitting, $z$ level, primitive equation ocean general circulation model of the Bryan-Cox-Semtner type. The model uses a Mercator grid with average $\frac{1}{4}^{\circ}$ horizontal resolution and 20 levels in the vertical. Further details of the model formulation are given by Semtner and Chervin (1992), Stammer et al. (1996) and Tokmakian and Challenor (1999). We use velocity output from the POCM_4C run of the model that was forced over a 20 year period (1979-1998) with daily varying fluxes of heat, freshwater and momentum. The fluxes were calculated from the European Centre for Medium-Range Weather Forecasts (ECMWF) reanalysis data set for the first part of the model run (1979-1993) and the ECMWF operational data set for the later part (1994-1998). Monthly mean model velocity fields are used in this investigation to eliminate aliasing of inertial oscillations (Jayne and Tokmakian, 1997). A comparison of satellite and in situ data found POCM_4C to produce a reasonable 
simulation of the circulation of the study area (Thorpe et al., 2004).

Particle transport from the Antarctic Peninsula region to South Georgia is simulated with a twodimensional second-order Runge-Kutta particletracking scheme that incorporates both horizontal advection and the effect of diffusion. The position of a particle at timestep $n+1\left[\mathbf{x}_{n+1}=\left(x_{n+1}, y_{n+1}\right)\right]$ is estimated from its position at timestep $n\left(\mathbf{x}_{n}\right)$ in two steps:

$\mathbf{x}_{n+1 / 2}^{*}=\mathbf{x}_{n}+\mathbf{v}_{n}\left(\mathbf{x}_{n}\right) \frac{\Delta t}{2}$,

$\mathbf{x}_{n+1}=\mathbf{x}_{n}+\mathbf{v}_{n+1 / 2}\left(\mathbf{x}_{n+1 / 2}^{*}\right) \Delta t+\mathbf{w}$,

where $\mathbf{x}_{n+1 / 2}^{*}$ is an estimate of the position of the particle at timestep $n+\Delta t / 2$ and $\mathbf{v}_{n}\left(\mathbf{x}_{n}\right)$ is the advective component of motion derived from the monthly mean velocity fields of POCM_4C at timestep $n$. $\Delta t$, the timestep, is set to 0.1 day to satisfy the Courant-Friedrich-Lewy stability criterion. $\mathbf{w}=(d \cos \Theta, d \sin \Theta)$ is a random walk that mimics two-dimensional horizontal diffusion (following Evans and Noye, 1995); $d=$ $\sqrt{12 D_{\mathrm{h}} \Delta t R_{1}}$ and $\Theta=2 \pi R_{2}$ where $D_{\mathrm{h}}$ is the horizontal diffusion coefficient and $R_{1}$ and $R_{2}$ are random numbers between 0 and 1 . We assume isotropic diffusion and use $D_{\mathrm{h}}=100 \mathrm{~m}^{2} \mathrm{~s}^{-1}$, the same order of magnitude as the large scale eddy diffusivity calculated for the study region (Olbers and Wenzel, 1989). Altering the value of $D_{\mathrm{h}}$ by
$50 \%$ and $500 \%$ does not affect the general pattern of results (Thorpe, 2001). The timestep used in the particle-tracking scheme requires interpolation between the velocity fields. This is performed following the method of Killworth (1996) in which the mean velocity fields are modified slightly to avoid errors associated with straightforward linear interpolation between monthly means.

To test the advection scheme and assess the near-surface circulation simulated by POCM_4C, particles were released into the modified velocity fields at the same point in space and time as 12 mixed-layer World Ocean Circulation Experiment (WOCE) drifters. The WOCE drifters were drogued at $15 \mathrm{~m}$ depth and released between 1990 and 1997 (Table 1; drifter trajectory data were obtained from the Marine Environmental Data Service, http://www.meds-sdmm.dfo-mpo.gc.ca). The particles in the POCM_4C velocity fields were tracked with just the advective part of the scheme (i.e., omitting the random walk).

The WOCE drifters illustrate the near-surface circulation of the Scotia Sea [Fig. 2(a)]. Those drifters released in the southwest of the study region travel northeastwards across the Scotia Sea. Of these, the two northernmost deployments (dark blue and jade trajectories) become entrained into the flow of the SACCF and reach the South Georgia shelf in approximately 4 months, while the more southerly drifters follow the mean path of the southern boundary of the ACC (SB) taking

Table 1

Deployment details of the WOCE drifters used in the sensitivity test

\begin{tabular}{|c|c|c|c|}
\hline ARGOS ID & Date & Position & $\begin{array}{l}\text { Colour used in } \\
\text { Fig. } 2\end{array}$ \\
\hline 22046 & 22.01 .1995 & $62.216^{\circ} \mathrm{S}, 56.717^{\circ} \mathrm{W}$ & Red \\
\hline 22047 & 21.01 .1995 & $61.471^{\circ} \mathrm{S}, 57.005^{\circ} \mathrm{W}$ & Light green \\
\hline 22048 & 02.03 .1995 & $59.417^{\circ} \mathrm{S}, 57.533^{\circ} \mathrm{W}$ & Dark blue \\
\hline 22049 & 20.01 .1995 & $60.417^{\circ} \mathrm{S}, 57.002^{\circ} \mathrm{W}$ & Orange \\
\hline 22577 & 24.09 .1994 & $53.492^{\circ} \mathrm{S}, 35.059^{\circ} \mathrm{W}$ & Magenta \\
\hline 22591 & 21.09 .1994 & $53.445^{\circ} \mathrm{S}, 40.118^{\circ} \mathrm{W}$ & Grey \\
\hline 24442 & 06.01 .1997 & $59.336^{\circ} \mathrm{S}, 49.163^{\circ} \mathrm{W}$ & Black \\
\hline 25573 & 17.05 .1996 & $59.937^{\circ} \mathrm{S}, 59.794^{\circ} \mathrm{W}$ & Jade \\
\hline 25576 & 17.05 .1996 & $54.904^{\circ} \mathrm{S}, 39.898^{\circ} \mathrm{W}$ & Purple \\
\hline 8911511 & 01.01 .1990 & $63.353^{\circ} \mathrm{S}, 60.701^{\circ} \mathrm{W}$ & Mid-blue \\
\hline 8911512 & 01.01 .1990 & $62.925^{\circ} \mathrm{S}, 60.048^{\circ} \mathrm{W}$ & Pink \\
\hline 8911514 & 01.01 .1990 & $61.533^{\circ} \mathrm{S}, 54.466^{\circ} \mathrm{W}$ & Green \\
\hline
\end{tabular}




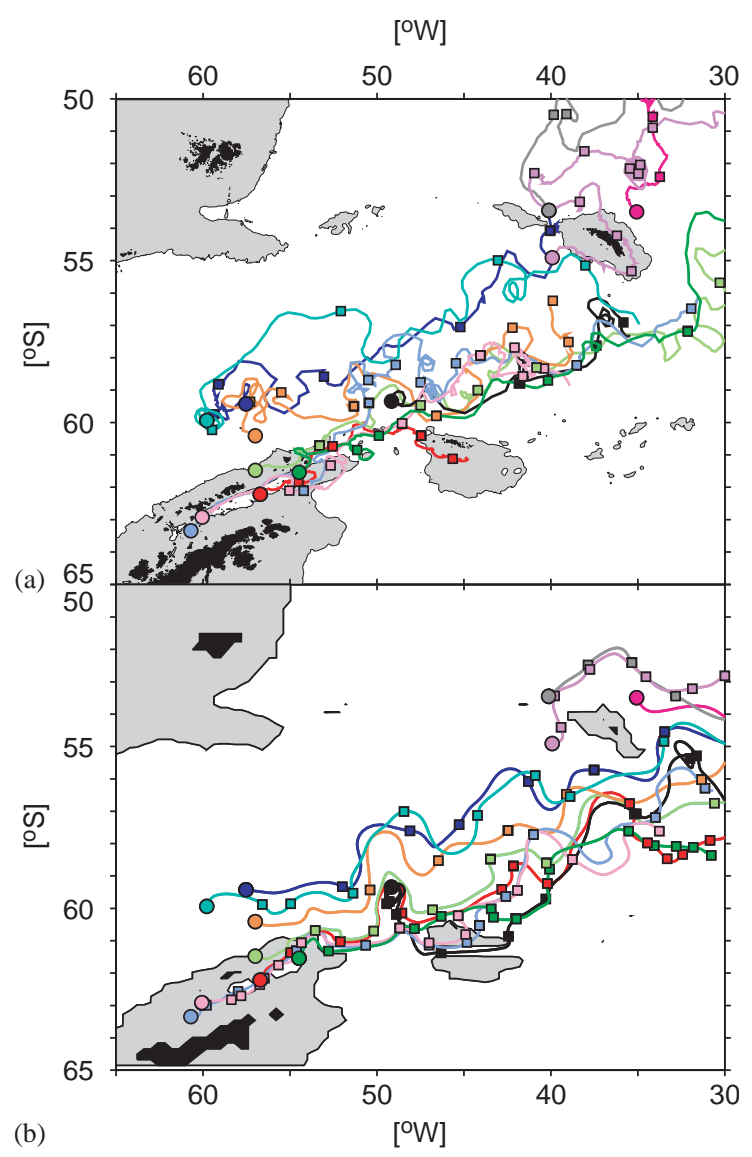

Fig. 2. (a) WOCE mixed-layer drifter trajectories; (b) trajectories simulated in the time-variant POCM_4C velocity fields. Circles mark drifter release locations and squares mark 30 day positions. Bathymetry [from Smith and Sandwell (1997) in (a) and POCM in (b)] shallower than $1000 \mathrm{~m}$ is shaded grey. Deployment details of the drifters and colour key are given in Table 1.

around 4-8 months to cross the Scotia Sea. Mean speeds of these two groups of drifters are $\sim 0.3$ and $\sim 0.25 \mathrm{~m} \mathrm{~s}^{-1}$, respectively. For comparison, in the eastern Scotia Sea estimates of the geostrophic velocity (relative to the deepest common level between individual station pairs) associated with the SACCF range from 0.075 to $0.35 \mathrm{~m} \mathrm{~s}^{-1}$ (Thorpe et al., 2002; Ward et al., 2002) and is about $0.15 \mathrm{~m} \mathrm{~s}^{-1}$ for the SB (Thorpe et al., 2002). The drifter released to the southwest of the South Georgia shelf (purple line; described in more detail by Thorpe et al., 2002) demonstrates anticyclonic flow around the island with retroflection of the flow to the northeast of South Georgia. The remaining two drifters, released to the north of South Georgia (grey and magenta), are carried rapidly northwards and exit the study region. The drifter trajectories illustrate the high levels of mesoscale activity present in the Scotia Sea with several drifters becoming caught in eddies.

Sensitivity tests demonstrated that the most realistic simulated trajectories were achieved when using velocity fields calculated at a depth of $25 \mathrm{~m}$ by averaging the upper two levels of POCM_4C (12.5 and $37.5 \mathrm{~m}$ depth) (Thorpe, 2001). The general northeastward flow from the Antarctic Peninsula to South Georgia is reproduced by POCM_4C [Fig. 2(b)] and some eddies are present in the monthly mean velocity fields. However, the anticyclonic flow around South Georgia is not simulated by POCM_4C and the flow north of South Georgia has a much stronger zonal component than the observations depict. The simulated drifters have much slower mean speeds than the WOCE drifters, which is only to be expected given the limited horizontal resolution of the model (e.g., Stevens and Killworth, 1992). The drifters associated with the SACCF in the observations (dark blue and jade trajectories) have mean speeds of less than $0.15 \mathrm{~m} \mathrm{~s}^{-1}$ in POCM_4C while the drifters associated with the SB in the observations (red, light green, black, mid-blue, pink and green) have modelled mean speeds of generally less than $0.1 \mathrm{~m} \mathrm{~s}^{-1}$. Accordingly, the transport times are much slower for all but one of these drifters in POCM_4C. The southern group of drifters takes about one and a half times longer in the model than in the ocean to cross the Scotia Sea from the Antarctic Peninsula region $(\sim 10$ months versus $\sim 6$ months) and the travel time of one of the two SACCF-related drifters (jade trajectory) increases to $\sim 7$ months (versus $\sim 4$ months in the ocean). The other simulated SACCF-related drifter (dark blue), despite having a mean speed equal to about half that of the WOCE drifter, has a similar travel time in the model compared with the WOCE drifter. This is accounted for by the fewer eddies that the modelled drifter encounters as compared with the observed drifter. 
To investigate the effects of oceanographic variability on advection to South Georgia, particles were released at the start of each month from July 1979 to June 1997 into $25 \mathrm{~m}$ velocity fields, representative of mixed-layer transport. Because advection of Antarctic krill is such an important issue for the South Georgia marine ecosystem, we chose release sites for the particles based on the distribution of krill eggs (Marr, 1962; Hofmann et al., 1998) to investigate the effects of physical variability on the transport routes from these regions. Five hundred particles were tracked each month from each of 22 sites (Fig. 1) to ensure that we captured the true variability introduced by the time-variant velocity fields rather than variability arising from the (random) diffusive component of motion. The monthly sets of particles were tracked until all the particles had left the study region or for a maximum of one year, whichever came first. Any particles that grounded during the study or left the study region took no further part in the simulations. Given the predominantly northeastward flow associated with the ACC in the study region, it is a fair assumption that the particles leaving the study domain would not be transported back into it.

To quantify transport to South Georgia and the variability therein, we defined a box around South Georgia centred on the island and including the shelf and surrounding deeper waters (Fig. 1). The box has dimensions $4^{\circ}$ latitude by $10^{\circ}$ longitude $(\sim 444.5 \times 649.2 \mathrm{~km}$, giving an approximate area of $3 \times 10^{5} \mathrm{~km}^{2}$ ), and covers the foraging area of Antarctic fur seals (Arctocephalus gazella), one of the species of higher marine predators that breeds on South Georgia (Boyd et al., 2002; Staniland and Boyd, 2003). The final size of the box chosen was based on results from sensitivity tests to ensure that the results we obtained were reproducible (Thorpe, 2001). The probability of reaching South Georgia from each monthly set of particle releases was determined from the number of particles that passed through this box.

\section{Results}

Examples of the particle trajectories derived from the tracking scheme are shown in Fig. 3. The general northeastward flow across the Scotia Sea from the Antarctic Peninsula is clear. The inclusion of diffusion causes a wide spread of the particles and means that many more regions of the Scotia Sea are accessible to the particles than when advection is considered on its own. The two sets of particles illustrated in Fig. 3 were released 1 year apart and their trajectories demonstrate the interannual variability introduced into the near-surface transport by the time variant velocity fields. Those particles released in January 1992 [Fig. 3(a)] generally remain further south and are not as tightly constrained at around $35^{\circ} \mathrm{W}$ as those released in January 1993 [Fig. 3(b)] which pass much closer to South Georgia and indeed cross the

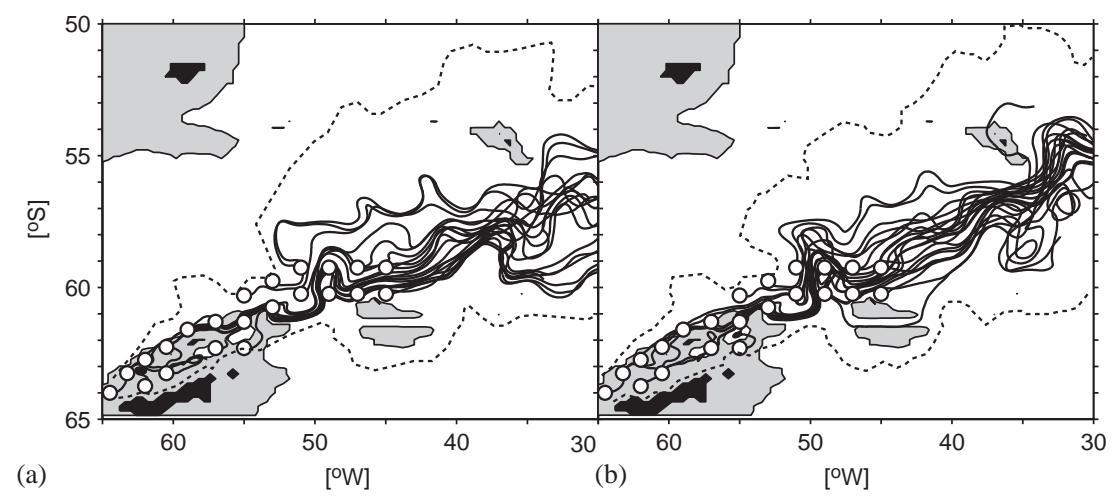

Fig. 3. Trajectories of particles released in (a) January 1992 and (b) January 1993 and tracked in time-variant POCM_4C velocity fields. Only the advective component of motion is shown for visual clarity; dashed lines mark the envelopes made by the trajectories calculated with both advection and diffusion. Model bathymetry shallower than $1000 \mathrm{~m}$ is shaded grey. 
shelf. These differences are reflected in the number of particles that reach South Georgia from these releases [Fig. 4(a)]: only 34\% of the particles released in January 1992 reach South Georgia (i.e. pass through the box marked in Fig. 1) compared with $67 \%$ of the January 1993 releases. The time series shows dramatic variability with occasions when only $14.5 \%$ of the particles reach the South Georgia region and other times when as many as $84 \%$ of the particles arrive there, suggesting substantial seasonal and interannual variability in the monthly velocity fields (the mean of the series is $51.9 \%$ of the particles reaching South Georgia with a standard deviation of $15.2 \%$ ). A seasonal signal can be distinguished in some of the years (mid-1980s) with a greater percentage of the particles released in the austral winter reaching South Georgia than of those released in the austral summer. This seasonal signal diminishes in the latter part of the series. However, a longer period of 3-5 years identified in the power spectrum of the series dominates the series (e.g., local minima in the series are evident in 1982, 1988, 1991/1992 and 1994). Also shown in Fig. 4(a) are the results from using a smaller and larger box to define the South
Georgia region $( \pm 20 \%$ increase in area of the box marked in Fig. 1). The series are clearly highly correlated (correlation coefficients of 0.96 and 0.98 respectively after removing the seasonal signal, significant at the 0.001 significance level), demonstrating that the results presented here are robust to the size of the box.

Large variability is also apparent in the mean time taken by the particles to reach South Georgia [Fig. 4(b)]. The mean transport times in the POCM_4C velocity fields range from 134.8 days to 221.4 days (4-7 months approximately) with a mean and standard deviation of 176.5 and 15.5 days, respectively. A much stronger seasonal signal is apparent in the time series of the transport time to South Georgia compared with the probability of the particles reaching South Georgia. Transport times tend to be longer for particles released in the austral summer than for those released in the austral winter. Longer period signals are not as clear in this series as in the series of probability of particles reaching South Georgia; however, there are clearly some years where the transport time is longer than in other years suggesting that there is variability with a longer than seasonal period in operation.
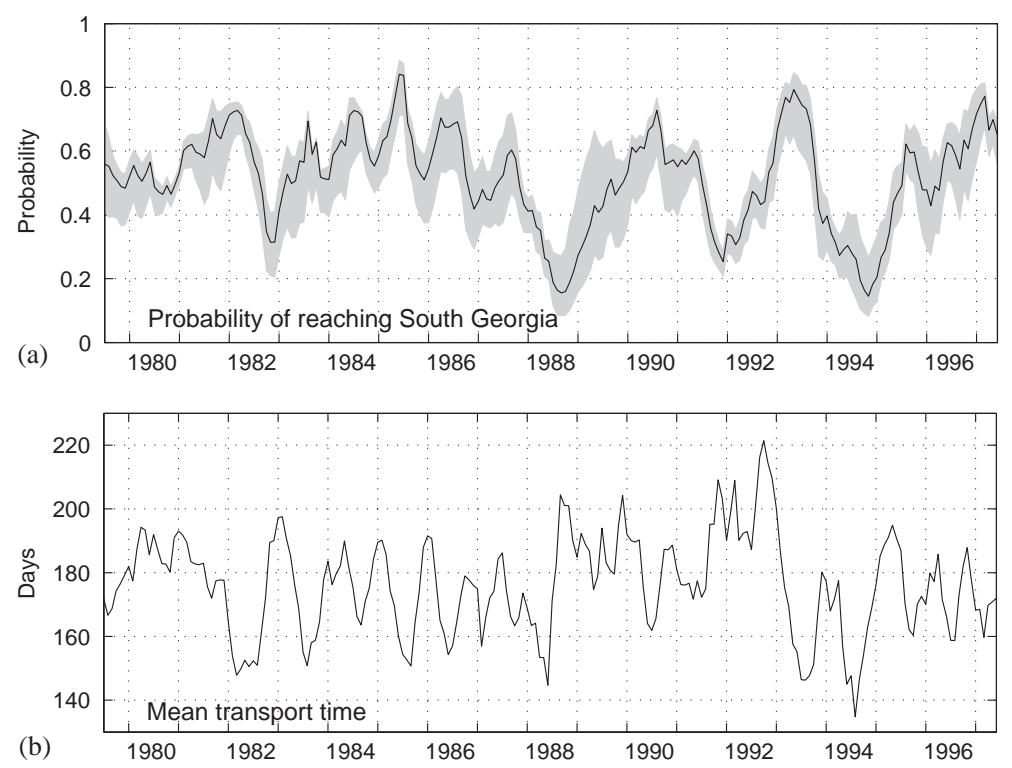

Fig. 4. Time series of the particle tracking results. (a) Probability of particles released each month reaching South Georgia (i.e. passing through the box marked in Fig. 1). The grey shading shows results from a $\pm 20 \%$ change in area of the box around South Georgia. (b) Mean time taken (days) for the particles to reach South Georgia. Results are plotted against the month of release. 


\section{Discussion}

Variability in the time-variant velocity fields of POCM_4C clearly affects the transport pathways and travel time to South Georgia on a number of timescales, from seasonal to longer periods. The period of 3-5 years observed in the time series of the probability of reaching South Georgia is in agreement with the period of the Antarctic Circumpolar Wave (ACW; Murphy et al., 1995; White and Peterson, 1996). Fig. 5 shows nearsurface temperature anomalies (at $12.5 \mathrm{~m}$, middepth of level 1 in the model) in the Scotia Sea in

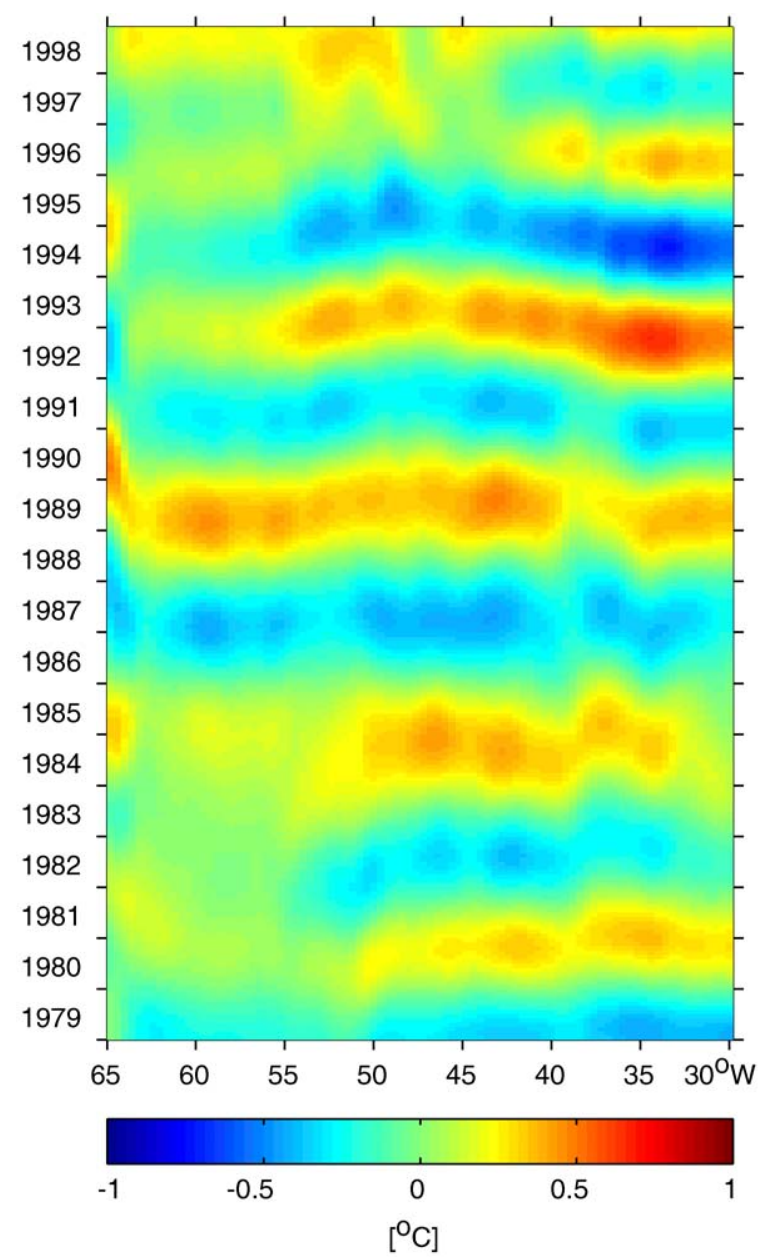

Fig. 5. Hovmoller diagram of filtered monthly anomalies of temperature at $12.5 \mathrm{~m}$ averaged over the Scotia Sea $\left(56^{\circ}-60^{\circ} \mathrm{S}\right)$ from POCM_4C $\left({ }^{\circ} \mathrm{C}\right)$. The data have been deseasonalised and filtered with a 3-7 year admittance bandpass filter.
POCM_4C over the 20 year run of the model, filtered with a bandpass filter with a 3-7 year admittance window (Duchon, 1979) following White and Peterson (1996). Large-scale variability has been reported in sea surface temperature data around South Georgia (Trathan and Murphy, 2003) and clearly affects the Scotia Sea in POCM_4C. Zhang and Semtner (2001) use POCM_4C as the ocean component of a global, high resolution, coupled ice-ocean model and observe a simulated ACW in the surface temperature, salinity and sea ice extent anomalies and in ocean temperature and salinity down to a depth of about $1000 \mathrm{~m}$. We observe an ACW-type signal in POCM_4C without a coupled ice model. If the ACW is a coupled ocean-atmosphere phenomenon (e.g. Qui and Jin, 1997; Peterson and White, 1998) and the atmospheric fields used to force an ocean model contain the ACW signal, then we would expect to see a signature of the ACW in the ocean model. Bonekamp et al. (1999) and Zhang and Semtner (2001) both note propagating and standing oscillations in ECMWF reanalysis atmospheric datasets. The first part of the POCM_4C run (1979-1993) was forced with ECMWF reanalysis fields and so it is therefore not surprising that there is a signal with the same characteristics as the $\mathrm{ACW}$ in POCM_4C. Thus although it is not unexpected for the POCM_4C output to contain an ACW-type signature, our results show that variability associated with the ACW could potentially have a large impact on the oceanic transport to South Georgia. Clearly, however, the 18 and 20 year time series (from the particle tracking and sea surface temperature analyses, respectively) used in our analyses are not long enough to fully resolve the long periodicity suggested by this research. More data over a longer timespan are required to properly determine the significant periods.

The success of the higher marine predators that breed on South Georgia depends on the local Antarctic krill population which is transported into the region from upstream of the island. Modelling studies have suggested that the Antarctic Peninsula region is one feasible source region for the South Georgia krill population (Hofmann et al., 1998; Murphy et al., 1998) and we have focussed on this transport route for our variability 
study. Our results have shown that there is strong variability in near-surface oceanic transport from the Antarctic Peninsula region to South Georgia. Changes in the velocity fields can strongly affect the probability of the water reaching South Georgia and the time taken to reach the island. Thus this has impacts on any passive tracers within the water such as larval krill which are found in the mixed layer (Hofmann et al., 1992). We have not attempted to accurately model the transport of adult krill by excluding behavioural traits such as vertical migration, swimming and active swarming. However, if, as in earlier modelling studies (Hofmann et al., 1998; Murphy et al., 1998; Fach et al., 2002), we assume that krill can be moved as passive tracers in large-scale ocean motion (Priddle et al., 1988), then our study strongly suggests that physical variability could be very important for the South Georgia marine ecosystem.

The box used to represent the South Georgia region (Fig. 1) covers the area that female Antarctic fur seals (Arctocephalus gazella) supporting pups on South Georgia forage in (Boyd et al., 2002; Staniland and Boyd, 2003) and thus, given the assumptions above and assuming that the variability observed in POCM_4C is representative of the ocean, the oceanic variability could affect the predators breeding on South Georgia. The long period of variability observed in our 20 year time series is the same period of variability that has been observed in the reproductive success of higher predators breeding on Bird Island, just to the west of South Georgia (Reid and Croxall, 2001, their Fig. 3). It is interesting that the model reproduces this same period of variability with clear years of high and low influx of water from the Antarctic Peninsula region. The variability recorded in the transport time to South Georgia from the Antarctic Peninsula could also be important for the influx of krill into South Georgia; a longer travel time of krill caught in the ocean currents increases the chances of mortality due to predation and lack of food on the journey but could also allow the krill to be at a later developmental stage on arrival at South Georgia (Fach et al., 2002).

It was noted from the Discovery Investigations in the 1930s that, around South Georgia, years could be characterised from sea surface temperature as warm or cold, associated with changes in the sea ice and the regional oceanography, in particular the inflow of water from the Weddell Sea (Marr, 1962; Deacon, 1977). Our particle tracking results suggest that there must be times when source regions other than the Antarctic Peninsula dominate the origin of water at South Georgia, with implications for the Antarctic krill population at South Georgia. Mackintosh (1972) and Baker (1977) showed that interannual fluctuations in the size of scientific catches of krill could be related to the prevailing oceanographic conditions, and Watkins et al. (1999) suggest that interannual variation in the krill population size composition observed at South Georgia could be related to different source regions of the krill from year to year.

Aside from the hypothesised effects on the South Georgia krill population, the near-surface transport variability observed in the POCM_4C output could affect the South Georgia ecosystem in other ways. Water of the southern ACC is influenced by the silicate-rich Weddell-Scotia Confluence (Gordon et al., 1977; Whitworth et al., 1994) found to the south of the ACC. Silicate is the only major nutrient recorded at growth-limiting concentrations in South Georgia waters and thus, variability in the origin of the waters around South Georgia could influence the primary production of the waters in the region (Whitehouse et al., 1996, 2000).

Our study has focussed on mixed layer transport which is relevant for larval krill (Hofmann et al., 1992). Adult krill are found throughout the upper $250 \mathrm{~m}$ of the water column (Murphy et al., 1998). A preliminary investigation into the effect of depth has shown that variability in transport pathways and time also exists when using depth-weight mean velocity fields of the upper $260 \mathrm{~m}$ of POCM_4C (the upper seven levels of the model) (Thorpe, 2001). Recent modelling work carried out using output from the Ocean Circulation and Climate Advanced Modelling project model (OCCAM; Webb et al., 1998) has investigated the effects of diel vertical migration on lagrangrian particle transport across the Scotia Sea (Murphy et al., 2004a). The authors superimposed a sinusoidal 
diel vertical migration over the upper $245 \mathrm{~m}$ and found that the migrating particles were slower than non-migrating particles travelling with the mean velocity over the same depth range. Some of the paths were almost identical to the nonmigrating particles but some were driven northward by the Ekman effect in the top layer. Thus the behaviour of older krill can affect the pathways of transport and this might be a useful future development of this research. Additionally, our experiments assumed a constant number of particles released each month but variability in the krill abundance and recruitment in the Antarctic Peninsula stocks has been recorded, suggested to be related to variability in the seaice (e.g., Loeb et al., 1997; Siegel et al., 1998). Ideally, future work would combine this biological variability with the oceanic transport variability to give a more accurate representation of the absolute transport of krill into the South Georgia region than our fixed number of releases each month.

\section{Acknowledgements}

We thank Robin Tokmakian for providing the POCM_4C output, Crispian Batstone for advice on filtering and colleagues from the British Antarctic Survey for helpful discussions. We are grateful to three anonymous reviewers for constructive comments that helped us to improve the manuscript. This research was funded by a Natural Environment Research Council CASE Ph.D. studentship between the University of East Anglia and the British Antarctic Survey.

\section{References}

Baker, A., 1977. Annual variations in krill catches. In: Deacon, G.E.R. (Ed.), Seasonal Variations in the Water Temperature and Salinity near South Georgia 1925-1937, Vol. 49. Unpublished IOS manuscript, pp. 5-6.

Bonekamp, H., Sterl, A., Komen, G.J., 1999. Interannual variability in the Southern Ocean from an ocean model forced by European Centre for Medium-Range Weather Forecasts reanalysis fluxes. Journal of Geophysical Research $104,13,317-13,331$.
Boyd, I.L., Arnould, J.P.Y., Barton, T., Croxall, J.P., 1994. Foraging behaviour of Antarctic fur seals during periods of contrasting prey abundance. Journal of Animal Ecology 63, 703-713.

Boyd, I.L., Staniland, I.J., Martin, A.R., 2002. Distribution of foraging by female Antarctic fur seals. Marine Ecology Progress Series 242, 285-294.

Chelton, D.B., Schlax, M.G., Witter, D.L., Richman, J.G., 1990. Geosat altimeter observations of the surface circulation of the Southern Ocean. Journal of Geophysical Research 95, 17,877-17,903.

Croxall, J.P., McCann, T.S., Prince, P.A., Rothery, P., 1988. Reproductive performance of seabirds and seals at South Georgia and Signy Island, South Orkney Islands, 1976-1987: implications for Southern Ocean monitoring studies. In: Sahrhage, D. (Ed.), Antarctic Ocean and Resources Variability. Springer, Berlin, pp. 261-285.

Croxall, J.P., Reid, K., Prince, P.A., 1999. Diet, provisioning and productivity responses of marine predators to differences in availability of Antarctic krill. Marine Ecology Progress Series 177, 115-131.

Deacon, G.E.R., 1977. Seasonal and annual variations in water temperature and salinity near South Georgia 1925-1937, Vol. 49. Unpublished IOS manuscript.

Duchon, C.E., 1979. Lanczos filtering in one and two dimensions. Journal of Applied Meteorology 18, 1016-1022.

Evans, P.L., Noye, B.J., 1995. A model for fast oil spill trajectory prediction in shallow gulfs. In: Bellwood, O., Choat, H., Saxena, N. (Eds.), PACON '94 Proceedings: Recent Advances in Marine Science and Technology PACON International and James Cook University of Northern Queensland, Australia, pp. 119-130.

Everson, I., 1984. Marine interactions. In: Laws, R. (Ed.), Antarctic Ecology, Vol. 2. Academic Press, London, pp. 783-819.

Fach, B.A., Hofmann, E.E., Murphy, E.J., 2002. Modeling studies of Antarctic krill Euphausia superba survival during transport across the Scotia Sea. Marine Ecology Progress Series 231, 187-203.

Gordon, A.L., Georgi, D.T., Taylor, H.W., 1977. Antarctic Polar Frontal Zone in the Western Scotia Sea-Summer 1975. Journal of Physical Oceanography 7, 309-328.

Hofmann, E.E., Capella, J.E., Ross, R.M., Quetin, L.B., 1992. Models of the early life history of Euphausia superba. Part I. Time and temperature dependence during the descentascent cycle. Deep-Sea Research 39, 1177-1200.

Hofmann, E.E., Klinck, J.M., Locarnini, R.A., Fach, B., Murphy, E., 1998. Krill transport in the Scotia Sea and environs. Antarctic Science 10, 406-415.

Jayne, S.R., Tokmakian, R., 1997. Forcing and sampling of ocean general circulation models: impact of high-frequency motions. Journal of Physical Oceanography 27, 1173-1176.

Killworth, P.D., 1996. Time interpolation of forcing fields in ocean models. Journal of Physical Oceanography 26, 136-143.

Loeb, V., Siegel, V., Holm-Hansen, O., Hewitt, R., Fraser, W., Trivelpiece, W., Trivelpiece, S., 1997. Effects of sea-ice 
extent and krill or salp dominance on the Antarctic food web. Nature 387, 897-900.

Mackintosh, N.A., 1972. Life cycle of Antarctic krill in relation to ice and water conditions. Discovery Reports $36,1-94$.

Marr, J., 1962. The natural history and geography of the Antarctic krill Euphausia superba Dana. Discovery Reports $32,33-464$.

Moore, J.K., Abbott, M.R., Richman, J.G., 1997. Variability in the location of the Antarctic Polar Front $\left(90^{\circ}-20^{\circ} \mathrm{W}\right)$ from satellite sea surface temperature data. Journal of Geophysical Research 102, 27,825-27,833.

Morrow, R., Coleman, R., Church, J., Chelton, D., 1994. Surface eddy momentum flux and velocity variances in the Southern Ocean from Geosat altimetry. Journal of Physical Oceanography 24, 2050-2071.

Murphy, E.J., Clarke, A., Symon, C., Priddle, J., 1995. Temporal variation in Antarctic sea-ice: analysis of a long term fast-ice record from the South Orkney Islands. Deep-Sea Research I 42, 1045-1062.

Murphy, E.J., Watkins, J.L., Reid, K., Trathan, P.N., Everson, I., Croxall, J.P., Priddle, J., Brandon, M.A., Brierley, A.S., Hofmann, E., 1998. Interannual variability of the South Georgia marine ecosystem: biological and physical sources of variation in the abundance of krill. Fisheries Oceanography 7, 381-390.

Murphy, E.J., Thorpe, S.E., Watkins, J.L., Hewitt, R., 2004a. Modelling the pathways of transport of krill in the Scotia Sea: spatial and environmental connections generating the seasonal distribution of krill. Deep Sea Research, in press.

Murphy, E.J., Watkins, J.L., Meredith, M.P., Ward, P., Trathan, P.N., Thorpe, S.E., 2004b. The Southern ACC Front to the northeast of South Georgia: horizontal advection of krill and its role in the ecosystem. Journal of Geophysical Research, 109, C01029, doi:10.1029/ 2002JC001522.

Nowlin, W.D., Klinck, J.M., 1986. The physics of the Antarctic Circumpolar Current. Reviews of Geophysics 24, 469-491.

Olbers, D., Wenzel, M., 1989. Determining diffusivities from hydrographic data by inverse methods with application to the Circumpolar Current. In: Anderson, D.L.T., Willebrand, J. (Eds.), Oceanic Circulation Models: Combining Data and Dynamics. Kluwer Academic Publishers, Dordrecht, pp. 95-139.

Orsi, A.H., Whitworth, T., Nowlin, W.D., 1995. On the meridional extent and fronts of the Antarctic Circumpolar Current. Deep-Sea Research I 42, 641-673.

Peterson, R.G., White, W.B., 1998. Slow oceanic teleconnections linking the Antarctic Circumpolar Wave with the tropical El Niño-Southern Oscillation. Journal of Geophysical Research 103, 24,573-24,583.

Priddle, J., Croxall, J.P., Everson, I., Heywood, R.B., Murphy, E.J., Prince, P.A., Sear, C.B., 1988. Large-scale fluctuations in distribution and abundance of krill - a discussion of possible causes. In: Sahrhage, D. (Ed.), Antarctic Ocean and Resources Variability. Springer, Berlin, pp. 169-182.
Qui, B., Jin, F.-F., 1997. Antarctic circumpolar waves: an indication of ocean-atmosphere coupling in the extratropics. Geophysical Research Letters 24, 2585-2588.

Reid, K., Croxall, J.P., 2001. Environmental response of upper trophic-level predators reveals a system change in an Antarctic marine ecosystem. Proceedings of the Royal Society of London B 268, 377-384.

Reid, K., Barlow, K.E., Croxall, J.P., Taylor, R.I., 1999a. Predicting changes in the Antarctic krill, Euphausia superba, population at South Georgia. Marine Biology 135, 647-652.

Reid, K., Watkins, J.L., Croxall, J.P., Murphy, E.J., 1999b. Krill population dynamics at South Georgia 1991-1997, based on data from predators and nets. Marine Ecology Progress Series 177, 103-114.

Semtner, A.J., Chervin, R.M., 1992. Ocean general circulation from a global eddy-resolving model. Journal of Geophysical Research 97, 5493-5550.

Siegel, V., Loeb, V., 1995. Recruitment of Antarctic krill Euphausia superba and possible causes for its variability. Marine Ecology Progress Series 123, 45-56.

Siegel, V., Loeb, V., Gröger, J., 1998. Krill (Euphausia superba) density, proportional and absolute recruitment and biomass in the Elephant Island region (Antarctic Peninsula) during the period 1977 to 1997. Polar Biology 19, 393-398.

Smith, W.F., Sandwell, D.T., 1997. Global seafloor topography from satellite altimetry and ship depth soundings. Science 277, 1956-1962.

Stammer, D., Tokmakian, R., Semtner, A., Wunsch, C., 1996. How well does a $1 / 4^{\circ}$ global circulation model simulate large-scale oceanic observations? Journal of Geophysical Research 101, 25,779-25,811.

Staniland, I.J., Boyd, I.L., 2003. Variation in the foraging location of Antarctic fur seals (Artocephalus gazella) and the effects on diving behaviour. Marine Mammal Science 19, 331-343.

Stevens, D.P., Killworth, P.D., 1992. The distribution of kinetic energy in the Southern Ocean: a comparison between observations and an eddy resolving general circulation model. Philophical Transactions of the Royal Society of London B 338, 251-257.

Thorpe, S.E., 2001. Variability of the southern Antarctic Circumpolar Current in the Scotia Sea and its implications for transport to South Georgia. Ph.D. Thesis, University of East Anglia, Norwich, UK.

Thorpe, S.E., Heywood, K.J., Brandon, M.A., Stevens, D.P., 2002. Variability of the southern Antarctic Circumpolar Current front north of South Georgia. Journal of Marine Systems 37, 87-105.

Thorpe, S.E., Stevens, D.P., Heywood, K.J., 2004. Comparison of two time-variant forced eddy-permitting global ocean models with hydrography of the Scotia Sea. Ocean Modelling, in press.

Tokmakian, R., Challenor, P.G., 1999. On the joint estimation of model and satellite sea surface height anomaly errors. Ocean Modelling 1, 39-52.

Trathan, P.N., Murphy, E.J., 2003. Sea surface temperature anomalies near South Georgia: relationships with the Pacific 
El Niño regions, Journal of Geophysical Research, 108, 8075, doi:10.1029/2000JC000299.

Ward, P., Whitehouse, M., Meredith, M., Murphy, E., Shreeve, R., Korb, R., Watkins, J., Thorpe, S., Woodd-Walker, R., Brierley, A., Cunningham, N., Grant, S., Bone, D., 2002. The Southern Antarctic Circumpolar Current Front: physical and biological coupling at South Georgia. DeepSea Research I 49, 2183-2202.

Watkins, J.L., Murray, A.W.A., Daly, H.I., 1999. Variation in the distribution of Antarctic krill Euphausia superba around South Georgia. Marine Ecology Progress Series 188, 149-160.

Webb, D.J., de Cuevas, B.A., 2003. The region of large sea surface height variability in the Southeast Pacific Ocean. Journal of Physical Oceanography 33, 1044-1056.

Webb, D.J., de Cuevas, B.A., Coward, A.C., 1998. The first main run of the OCCAM global ocean model. Internal Document 34, Southampton Oceanography Centre.
White, W.B., Peterson, R.G., 1996. An Antarctic circumpolar wave in surface pressure, wind, temperature and sea-ice extent. Nature 380, 699-702.

Whitehouse, M.J., Priddle, J., Symon, C., 1996. Seasonal and annual change in seawater temperature, salinity, nutrient and chlorophyll $a$ distributions around South Georgia, South Atlantic. Deep-Sea Research I 43, 425-443.

Whitehouse, M.J., Priddle, J., Brandon, M.A., 2000. Chlorophyll/nutrient characteristics in the water masses to the nor th of South Georgia, Southern Ocean. Polar Biology 23, 373-382.

Whitworth, T., Nowlin, W.D., Orsi, A.H., Locarnini, R.A., Smith, S.G., 1994. Weddell Sea Shelf Water in the Bransfield Strait and Weddell Scotia Confluence. DeepSea Research I 41, 629-641.

Zhang, Y., Semtner, A.J., 2001. The Antarctic Circumpolar Wave in a global, high-resolution, coupled ice-ocean model. Annals of Glaciology 33, 539-544. 